IZA DP No. 5170

The Dilemma of Delegating Search:

Budgeting in Public Employment Services

John T. Addison

Martin Altemeyer-Bartscher

Thomas Kuhn

September 2010 


\title{
The Dilemma of Delegating Search: Budgeting in Public Employment Services
}

\author{
John T. Addison \\ University of South Carolina \\ and IZA
}

Martin Altemeyer-Bartscher

Chemnitz University of Technology

Thomas Kuhn

Chemnitz University of Technology

Discussion Paper No. 5170

September 2010

\author{
IZA \\ P.O. Box 7240 \\ 53072 Bonn \\ Germany \\ Phone: +49-228-3894-0 \\ Fax: +49-228-3894-180 \\ E-mail: iza@iza.org
}

Any opinions expressed here are those of the author(s) and not those of IZA. Research published in this series may include views on policy, but the institute itself takes no institutional policy positions.

The Institute for the Study of Labor (IZA) in Bonn is a local and virtual international research center and a place of communication between science, politics and business. IZA is an independent nonprofit organization supported by Deutsche Post Foundation. The center is associated with the University of Bonn and offers a stimulating research environment through its international network, workshops and conferences, data service, project support, research visits and doctoral program. IZA engages in (i) original and internationally competitive research in all fields of labor economics, (ii) development of policy concepts, and (iii) dissemination of research results and concepts to the interested public.

IZA Discussion Papers often represent preliminary work and are circulated to encourage discussion. Citation of such a paper should account for its provisional character. A revised version may be available directly from the author. 
IZA Discussion Paper No. 5170

September 2010

\section{ABSTRACT \\ The Dilemma of Delegating Search: Budgeting in Public Employment Services}

The poor performance often attributed to many public employment services may be explained in part by a delegation problem between the central office and local job centers. In markets characterized by frictions, job centers function as match-makers, linking job seekers with relevant vacancies. Because their search intensity in contacting employers and collecting data is not verifiable by the central authority, a typical moral hazard problem can arise. To overcome the delegation problem and provide high-powered incentives for high levels of search effort on the part of job centers, we propose output-related schemes that assign greater staff capacity to agencies achieving high strike rates.

JEL Classification: J64, D82

Keywords: matching unemployment, public employment service, delegation problem, moral hazard, search theory

Corresponding author:

John T. Addison

Department of Economics

Darla Moore School of Business

University of South Carolina

1705 College Street

Columbia, SC 29208

USA

E-mail: ecceaddi@moore.sc.edu 


\section{Introduction}

In this paper we provide an incentive-compatible mechanism for the optimal funding of the public employment service, which is commissioned to minimize job match unemployment in the labor market. Frictions characterize even regular labor markets because information about job offers and job seekers is neither costless nor easy to obtain, so that it may take some not inconsiderable amount of time to effect successful job matches in the labor market. Moreover, the delegation of information gathering to job seekers might be inefficient to some extent due to the public good features of information. The need to smooth such frictions explains the actions of numerous governments in setting up public employment services. Such agencies may on searchtheoretic grounds be regarded as matchmakers, providing unemployed workers with information about vacancies. ${ }^{1}$ Search theory predicts that public employment services will support job seekers in part by increasing the intensity of job search. The greater the number of contacts made, the greater the strike rate and the lower the expected average duration of unemployment.

However, there is empirical evidence that the matching outcomes attained by publicly provided employment services in many European countries are lamentable (see, for example, Addison and Portugal, 2002, who document the poor outcomes achieved by the Portuguese public employment service). ${ }^{2}$ One potent source of failure may reflect agency considerations inherent in delegating the task of search to others. The present paper exploits such notions. It first sketches the nature of the incentivestructure within the public employment system before deriving optimal budgeting schemes that can overcome the agency problem.

We argue that a hidden action problem dogs public employment systems. Although the main economic rationale for setting up a public employment service is rooted in the lack of information in labor markets, with frictions on both sides of the market limiting beneficial trades, consider the problem inherent in the structure of the public employment service. The organization consists of a central employment office (the principal) which delegates the task of gathering information about vacancies to

\footnotetext{
${ }^{1}$ We regard the job center as a matchmaker acting in similar fashion to a שִידוּכִים (shidduch) or yenta in Jewish communities arranging marriages between the children of suitable families.

2 Earlier such studies include Wielgosz and Carpenter, 1987; Jones, 1988; Blau and Robbins, 1990; WinterEbmer, 1991; Bishop, 1993. However, for a more optimistic view, see Gregg and Wadsworth, 1996;

Thomas, 1997.
} 
local job centers (the agents). An informational gap between the central employment office and the job center opens up as the latter goes about its business. Specifically, agents entrusted with gathering data on job vacancies learn by doing. In these circumstances, the agent's effort cannot be observed by the principal, and if the realized unemployment rate is only a noisy signal of the local job center's search effort a moral hazard problem arises naturally from the delegation of the search function. A second main ingredient of this moral hazard problem is the conflict between agent and principal about the nature of the employment service to be offered. Agents that act as intermediaries in the labor market search process have to bear the cost of the search effort necessary to effectively combat matching unemployment while the central employment office seeks to implement the government's labor market policy at the lowest budget cost. Consequently, a job center tends to reduce unobservable search effort if the 'random' unemployment rate compounds the job center's search effort and pure luck.

To illustrate the moral hazard problem we shall present a model in which a risk averse job center chooses its search effort and the binary outcome of the search process (the unemployment rate) can be either high or low. First, we show that an incentivecompatibility constraint must be met inducing a high search effort on part of the job center. Second, we introduce a constraint defining the maximum work load that can be demanded of placement officers by the central employment service. The set of incentivefeasible budgeting mechanisms must satisfy these two constraints. Among the set of incentive-feasible schemes, we seek to identify those that achieve high search effort at minimum cost. In general, the incentive-compatibility constraint is binding if effort is unobservable. Therefore, the central employment office must offer an information rent in the second-best optimum.

Apart from these informational and physical constraints, we also take into account the following institutional constraint. Typically, in many European nations, the principal cannot offer monetary transfer payments to local agents by way of compensating them for high search effort. $^{3}$ Obviously, the lack of such policy

\footnotetext{
${ }^{3}$ A rare example of contracts including compensation payments for government staff is given by Walsh (1995), who proposes payments to central bankers contingent on their curbing the inflation rate. Examples are more numerous in the case of public utilities, which may be able to retain some of the benefits of greater than projected productivity increases in (otherwise) average cost pricing regimes. With the 2007 reform of the salary system in the German public service (Tarifvertrag für den öffentlichen Dienst, or TVöD) some 1 percent of the
} 
instruments considerably limits the scope for incentive-feasible budgeting by the central employment office. This may be the prime reason why many public-sector facilities appear to function so inefficiently. In order to sidestep these institutional shortfalls, we offer an alternative scheme that dispenses with monetary side payments. Instead, the central employment office assigns staff to local job centers contingent on the underlying unemployment rate.

In a repeated relationship, the principal can offer a budgeting plan that predetermines the capacity of the staff assigned to the agent in the following period. Hence, the job center undertakes its mission with a given staff capacity. It has the prospect of gaining additional capacity in the next budget period if the unemployment rate outcome is low. That said, in our model the central employment office clearly cannot effectively punish job centers that deliver a poor outcome by assigning them a very small staffing capacity in following period on account of the work load constraint. Accordingly, there is a trade-off between the latter and the incentive-compatibility constraint.

In complete information settings, a constant staff capacity is assigned to a risk averse job center so as to provide full insurance. In a setting with unobservable effort, however, the central employment office must shift some risk on to the local job center to meet the incentive-compatibility constraint. Such a budgeting scheme can only be implemented if the risk averse job center receives a risk premium in the lucky case. Otherwise, the work load constraint will not be met. Hence, the central employment office faces a conflict between the work load constraint and the incentive-compatibility constraint of the job center. On the one hand, the central employment office should offer contracts that make local job centers in part a residual claimant of the matching outcome (unemployment rate) to incentivize search effort. On the other hand, it must take especial care that agents in the job center are not overloaded with work.

The budgeting scheme we envisage is similar to a mechanism already in place in other areas of the public sector. But perhaps the most obvious example is home grown. Consider a professor of economics who applies for funding from the National Science

total salary payment can be paid as an output-related compensation. Section 18 of the TVöD allows for an expansion of the incentive component up to 8 percent in the future. Currently, however, the magnitude of the incentive component falls far short of providing high powered incentives and this is underscored by the fact that the scope for making incentive payments under section 18 is tightly limited. 
Foundation. Exerting high effort increases research output today and enhances the likelihood of obtaining funding in the next period. Vulgo: funding from the NSF offers the prospect of an increase in staff capacity tomorrow.

Our paper is firmly rooted in three strands of the broader literature. In the first place, it is related to the literature seeking to analyze the efficiency of operation of the public employment service. Closest in spirit perhaps is Sheldon's (2003) comparatively recent analysis of the efficiency of the Swiss public employment service using a nonparametric matching function. Relatedly, Petrongolo and Pissarides (2001) survey the micro-foundations, empirical evidence, and estimation issues underlying the aggregate matching function. The specific functional form of the matching technology that is assumed in the frame of our model is in line with the foundations of these two important contributions. Additionally, we highlight the delegation problems that may be the very source of the inefficiencies in the public employment service identified by Sheldon (2003).

Necessarily we also refer to the search-theoretic literature based on frictional transactions in labor markets arising from incomplete information. In line with this strand of the wider literature, we assume that unemployed job seekers must devote time and other resources to locate an adequate position (see Mortensen, 1970, 1986; Gronau, 1971; McCall, 1970, Lippman and McCall, 1976; Merz, 1995). In particular, we refer to models that treat search intensity as an endogenous variable. Here it is shown that search intensity is costly in terms of effort input and/or additional time spent on job search. However, the contact rate is assumed to be an increasing function of search effort taken by job seeker, or by those supporting them (see Rogerson, Shimer, and Wright, for a survey of this literature).

But of course our main interest devolves around a solution to the delegation problem within the public employment service. We therefore we employ a principalagent model consistent with the efficiency wage theory of Shapiro and Stiglitz (1984) and Grossman and Hart's (1982) theory of a managerial firm. A distinctive feature in our paper is the repeated relationship between principal and agent, in line with Chiappori, Macho, Rey, and Salanié (1994). Further, as intimated earlier, our model contains a payoff function of the agent containing non-monetary compensation for effort. Unlike the standard model, effort cost and compensation are non-separable in our treatment. 
The outline of the paper is as follows. We first describe the basic principal-agent relationship, including the objective functions of the central employment office and the job center. We next outline a first-best optimal budget plan that an omniscient central employment office would offer to the job center. The first-best outcome then serves as a reference solution for our optimal budgeting scheme. A summary concludes.

\section{The Basic Model and Problem}

\section{Job match unemployment}

Our basic assumption is that information about what is available on the labor market is not easy to obtain. In particular, search on the part of unemployed workers for a satisfactory vacancy takes time and involves some material search effort. In line with standard search-theoretic reasoning, match unemployment - the time unemployed workers search for a job - depends crucially on the contact rate $\alpha$. This contact rate indicates the arrival number of job offers of which the unemployed worker learns and can choose between. Thus, the unemployment rate is expressed as a decreasing function of the contact rate, given by $U(\alpha) .{ }^{4}$ In practice, the contact rate will depend on many influences that are determined outside of the model; examples include the business cycle, region-specific shocks, and behavioral factors. The stochastic contact rate $\tilde{\alpha}$ in our model may be expected to reflect such elements. In particular, it can take two values $\left\{\alpha_{1}, \alpha_{2}\right\}$, with $\alpha_{1}-\alpha_{2}>0$. Equivalently, we can refer to a situation with a high contact rate $\alpha_{1}$, yielding a low unemployment rate $U\left(\alpha_{1}\right)=U^{1}$, as the "lucky case" and $\alpha_{2}$ with $U\left(\alpha_{2}\right)=U^{2}$ as the "unlucky case."

\section{The public employment service}

Governments in most nations provide a public employment service $s$ offering contacts (information about available jobs) to unemployment workers. In our model, the employment service $s$ describes the intensity of job placement activities undertaken by a job center for each job seeker. The intensity of job placement activities does not simply express the time devoted by a placement officer to an individual client. It further comprises counseling sessions, plus substantial data retrieval and career guidance. As

\footnotetext{
${ }^{4}$ In line with the basic search-theoretic model, we consider a steady state unemployment rate that is a decreasing function of the contact rate. The steady state unemployment rate is given by $U(\alpha)=$ $\frac{\delta}{\delta+\alpha \cdot\left(1-F\left(w_{R}\right) \alpha\right)}$, where $\delta$ is the discount factor, $F(\cdot)$ is the cumulative distribution function of the wage $w$ offered by firms, and $w_{R}$ is the reservation wage formulated to maximize (the job seekers') life-time income.
} 
the job center can be interpreted as a vertically integrated entity in the public employment system we consider the service $s$ as an intermediate product used as an input in the overall search process whose output is the expected unemployment rate $U^{i}$.

In particular, we assume that the influence of the employment service $s$ on the stochastic contact rate is characterized by the probabilities of the "lucky case" and the "unlucky case," conditional on the level of the public employment service $s$, namely $p\left(\alpha_{1} \mid s\right)=1-p\left(\alpha_{2} \mid s\right)$. Technically speaking, the service level could take an arbitrary value in $s \in \mathbb{R}_{+}$. However, in the frame of the game with asymmetric information, it is reasonable to assume that there is some threshold service level $s^{0}$ which must be provided so that the employment service has a noticeable effect. In particular, we assume that the central employment office can detect if the job center provides a service level below the critical $s^{0}$. Above the threshold $s^{0}$ however the central employment office cannot quantify the service level. Intrinsically, the matching process is improved if a high-volume employment service is provided. In particular, the "lucky case" is more likely if the amount of the service is high in the sense of first-order stochastic dominance. In particular, this means that the distribution function $p\left(\alpha_{i} \mid s\right)$ is a decreasing and convex function of s. Then, the expected value $E\left[U^{i} \mid s\right]$ is an increasing and concave function of the employment service. ${ }^{5}$

\section{The technology of the search process}

The employment service $s$ provided by the local job center can be considered as an intermediate product, whose inputs are labor $L$ and effort $e$, with $L \in \mathbb{R}_{+}$and $e \in \mathbb{R}_{+}{ }^{6}$ More labor must be used in order to offer a more time consuming service $s$. As a second input and importantly for the analysis in our paper, the search for job vacancies calls for special initiatives by the staff in the job center, including firm contacts and/or career guidance. These special initiatives are represented by search effort $e$. Familiarly, the well-behaved production technology of the employment service depending on labor input $L$ and search effort $e$ can be written $s=s(L, e)$, with $s_{e}(L, e)>0, s_{e e}(L, e)<0$, $s_{L e}(L, e)>0, s_{L}(L, e)>0, s_{L L}(L, e)>0$. Further, the value of the production function is zero at zero effort of labor and the limit of the derivative towards zero effort or labor is positive infinity. Further, we normalize the wage rate of staff $L$ employed in the local job

\footnotetext{
${ }^{5}$ See Appendix A.1.

${ }^{6}$ See Sheldon's (2003) for a similar interpretation of search technology.
} 
center to unity. The disutility for the staff of the job center associated with search effort $e$ is given by the function $\psi(e)$ with $\psi^{\prime}(e)>0$ and $\psi^{\prime \prime}(e) \geq 0$.

\section{Dynamic setting and timing within a sub-game}

Consistent with the search-theoretic framework, the principal-agent relationship between the central employment office and the local job center is a repeated one. In line with the general setting of the search-theoretical model, we consider an infinite time horizon, where the periods are denoted by $t$, with $t=1,2, \ldots, \infty$ as well as a discount rate $\delta$, which is valid for either the principal or the agent, with $0<\delta<1$. We assume that the principal possesses some commitment devices in order to offer a budgeting plan that predetermines the capacity or employment size of the agency in the following period $t+1$ contingent on the observed outcome in $t$. However, the principal has no commitment power to implement a long-term contract that sets out in advance a scheme for more than one period. This seems to be rather strong assumption on contract-theoretical grounds. However, in real world applications, the central employment office has typically a limited planning horizon. Accordingly, we denote by $L_{t+1}^{i}=L_{t+1}\left(U_{t}^{i}\right)$ the staff capacity assigned to the job centre in period $t+1$ if employment rate $U_{t}^{i}$ in period $t$ is observed. Further, the variables $e_{t}, s_{t}$, and $U_{t}^{i}$ signify the effort level, the employment service, and the unemployment rate, respectively, in the corresponding period $t$. The timing of the game at arbitrary points in time $t$ and $t+1$ sees the players subsequently acting as follows:

Stage 1.t First, in period $t$, the central employment office offers budgeting scheme $L_{t+1}^{i}=L_{t+1}\left(U_{t}^{i}\right)$ for $i=1,2$ to the local job center;

Stage 2.t In the second step, also in period $t$, the local job office chooses an employment service $s_{\mathrm{t}}$. The employment service is effected by exerting search effort e, given the current staff capacity $L_{t}^{i}=L_{t}\left(U_{t-1}^{i}\right)$;

Stage 3.t+1 Third, nature draws a contact rate $\alpha_{i}$ from a distribution conditional on $\mathrm{s}_{\mathrm{t}}$ which affects the unemployment rate in the following period $t+1$.

Stage 4.t+1 Finally, the budgeting scheme $L_{t+1}^{i}=L_{t+1}\left(U_{t}^{i}\right)$ is executed in the following period $t+1$. 
Due to the limited commitment power, the central employment office offers a new contract $L_{t+2}^{i}\left(U_{t+1}^{i}\right)$ in $\mathrm{t}+1$ contingent on the unemployment rate $U_{t+1}^{i}$.

\section{The objective function of the central employment office}

We assume that the central employment office seeks to minimize the overall cost of the public employment service necessary to establish an exogenously given level of service $s=s^{*}$. Accordingly, it assigns a certain staff capacity to job centers in period $\mathrm{t}+1$ contingent on the output level observed in period t. As the size of the staff $L_{t}^{i}$ assigned to the job center in the previous period $t-1$ is a sunk cost for the central employment office, it can be omitted in the objective function:

$$
p\left(\alpha_{1} \mid s_{t}\right) \delta L_{t+1}^{1}-p\left(\alpha_{2} \mid s_{t}\right) \delta L_{t+1}^{2}
$$

Note that the central employment office is risk neutral to stochastic (per-period) unemployment insurance payments as its objective function is linear in the outcome $U_{i}$.

Objective function of the local job center

The job center deploys a constant labor capacity that is predetermined by the central office. It can choose the employment service $s_{t}$ by exerting costly search effort $e_{t}$. The per-period utility function of the job center can be written:

$$
V\left(e_{t}\right)=z-\psi\left(e_{t}\right) \text { for } t=1, \ldots, \infty \text {, }
$$

where $z$ is a constant utility from labor income. Different to the central employment office the job center is risk averse to a lottery of staff capacity.

In the remainder of the paper we will often make use of the inverse of the intermediate production function $s_{t}=s\left(e_{t}, L_{t}^{i}\right)$. The inverse function tells us how much effort $e_{t}$ the staff in the job center must exert in order to achieve a given employment service $s_{t}$ via a given staff capacity $L_{t}^{i}$, namely $e_{t}=e\left(s_{t}, L_{t}^{i}\right)$. Accordingly, the marginal cost of the employment service $s_{t}$ from the viewpoint of the job center, confronted with a fixed capacity of staff $L_{t}^{i}$, is:

$$
M C\left(s_{t}\right)=\frac{\psi r\left(e_{t}\right)}{s_{e}\left(L_{t}^{i}, e_{t}\right)}
$$


The marginal cost function of the employment service $s_{t}$, denoted by $M C\left(s_{t}\right)$ is an increasing function in service $s_{t}$. Further, by the quasi-concavity of the intermediate production technology $s\left(L_{t}^{i}, e_{t}\right)$, coupled with the ceteris paribus assumption, the value of $M C\left(s_{t}\right)$ is the lower the higher staff capacity $L_{t}^{i}$ (see Appendix A.1).

Moreover, in line with the standard literature on hidden action, we consider a maximum work load that can be set by the central authorities within a period to provide a given employment service $s_{t}$. Formally, the work load constraint is identical to the individual rationality constraint in the standard principal-agent model. Here, we shall assume that the job-center agents can inter-temporally balance the risk of a low unemployment rate within the two-period horizon. In the particular framework of the present model, one can think of the maximum workload as being determined by a union that may elect to go on strike if it is not met because of an insufficient capacity of the staff. However, as we will show below, the main results would not change if the work load constraint had strictly to be met within one period. ${ }^{7}$ The agent's expected pay-off in the two-period horizon is given by:

$$
V\left(e\left(s_{t}, L_{t}^{i}\right)\right)+\delta p\left(\alpha_{1} \mid s_{t}\right) V\left(e\left(s_{t+1}, L_{t+1}^{1}\right)\right)+\delta p\left(\alpha_{2} \mid s_{t}\right) V\left(e\left(s_{t+1}, L_{t+1}^{2}\right)\right)
$$

Assuming that the overall reservation utility of placement officers is given by an exogenously given reservation utility $D$, we can formulate the maximum work load constraint (WC) as follows:

$$
\begin{gathered}
V\left(e\left(s^{*}, L_{t}^{i}\right)\right)+\delta p\left(\alpha_{1} \mid s_{t}^{*}\right) V\left(e\left(s_{t+1}, L_{t+1}^{1}\right)\right)+\delta p\left(\alpha_{2} \mid s_{t}^{*}\right) V\left(e\left(s_{t+1}, L_{t+1}^{2}\right)\right) \geq \\
(1-\delta) D, \text { either for } L_{t}^{1} \text { or for } L_{t}^{2} \text { for all } i
\end{gathered}
$$

Using the objective function of the job center (2), we can equivalently write:

$$
\begin{aligned}
\psi\left(e\left(s^{*}, L_{t}^{i}\right)\right)+ & \delta p\left(\alpha_{1} \mid s_{t}^{*}\right) \psi\left(e\left(s_{t+1}, L_{t+1}^{1}\right)\right)+\delta p\left(\alpha_{2} \mid s_{t}^{*}\right) \psi\left(e\left(s_{t+1}, L_{t+1}^{2}\right)\right) \\
& \leq(1+\delta)(z-D), \text { either for } L_{t}^{1} \text { or for } L_{t}^{2} \text { for all } i .
\end{aligned}
$$

The maximum workload constraint WC crucially depends on three variables: the current staff capacity $L_{t}^{i}$; the lottery of staff capacity in the following period $E\left(L_{t+1}^{i}\right)$; and the certain amount of services to be provided in the current period $t$ and in the following period $t+1$, namely $s_{t}^{*}$. For given a current staff capacity $L_{t}^{i}$ and levels of service $s_{t}^{*}$ the

\footnotetext{
${ }^{7}$ The case where the workload constraint must be strictly met within one period is in line with the limited liability constraint in the standard principal-agent literature.
} 
central employment office must offer a budgeting plan that promises a sufficiently high expected level of staffing $E\left(L_{t+1}^{i}\right)$. Otherwise, the job center's reservation utility D will not be met. Further, for a given level of service $s_{t}^{*}$, single placement officers must exert higher costly search effort $e_{t}$ if the staff capacity is low. This again calls for a higher expected level of staffing $E\left(L_{t+1}^{i}\right)$ as stated in Lemma 1. Here, either the job center is confronted with a low capacity of $L_{t}^{2}$, due to a low output in the previous period $t-1$, or with a high capacity $L_{t}^{1}$, due to a high output in period $t-1$.

Lemma 1: The capacity of the staff which is assigned to the job center in period $t+1$ crucially depends on the capacity in the previous period $t$ : If the staff capacity $L_{t}^{i}$ is relatively high the central office can offer a more opportune lottery of staff capacity for the following period $L_{t+1}^{i}$.

Proof: see Appendix A.2.

\section{First-Best Optimal Budgeting}

As a benchmark, we initially assume that the central employment office can observe the performance of the employment service $s_{t}^{*}$ that is locally provided in every period $t$. For a given level of service $s_{t}^{*}$, it implements the least-cost combination of inputs $L_{t}^{i}$ and $e_{t}$ by assigning staff capacity. Here we assume that the central employment office can punish the local job center, if the latter do not comply with the contractual terms or targets. ${ }^{8}$ Additionally, the central employment office must take into account that the endeavor of the job center is limited and crucially depends on staffing.

As an added complication, we have also to recognize that the central employment office effectively cannot make monetary compensatory payments to its agencies. This is because the German public service salary system (or TVöD) contains an incentive component amounting to just 1 percent of the salary. And similar regulations are in place in other European nations more generally. Rather, the reward will take the form of additional staff that the central employment office assigns to the job center. As such labor is also used to produce the observed outcome - the public employment service -

\footnotetext{
8 In real world applications, the central employment office may hardly punish a local job center that fails to fulfill its duties. Here, we eschew discussion of the possible institutional constraints that may avoid punishment of the local job center as the full information case should be chiefly regarded as a benchmark solution.
} 
'compensation' in terms of a higher staff can only be provided with a time lag of at least one period.

Let us consider the minimization problem of principal at a arbitrary point of time $t$ :

$$
\begin{gathered}
\min _{\left\{L_{t+1}^{1}, L_{t+1}^{2}\right\}} p\left(\alpha_{1} \mid s_{t}\right) \delta L_{t+1}^{1}+p\left(\alpha_{2} \mid s_{t}\right) \delta L_{t+1}^{2} \\
\text { subject to (WC) and } s=s_{t}^{*} .
\end{gathered}
$$

Lagrange's method yields the following first order condition w.r.t. the staff capacity $L_{t+1}^{1}, L_{t+1}^{2}$ in the "lucky" and "unlucky" cases, respectively:

$$
\frac{\psi^{\prime}\left(e\left(s_{t}^{*}, L_{t+1}^{1}\right)\right) s_{L}\left(e_{t}, L_{t+1}^{1}\right)}{s_{e}\left(e_{t}, L_{t}^{1}\right)}=\lambda_{t}=\frac{\psi^{\prime}\left(e\left(s_{t}^{*}, L_{t+1}^{2}\right)\right) s_{L}\left(e_{t}, L_{t+1}^{2}\right)}{s_{e}\left(e_{t}, L_{t}^{2}\right)} .
$$

Via equation (3), the first order condition (6) may be written:

$$
\operatorname{MC}\left(s_{t}^{*}\left(e_{t}, L_{t+1}^{1}\right)\right) s_{L}\left(e_{t}, L_{t+1}^{1}\right)=\lambda_{t}=\operatorname{MC}\left(s_{t}^{*}\left(e_{t}, L_{t+1}^{2}\right)\right) s_{L}\left(e_{t}, L_{t+1}^{2}\right) .
$$

The first order condition with respect to the assignment of staff to the job center contingent on the state of the nature yields the optimal coinsurance between principal and agent due to the Borch rule. ${ }^{9}$ As the principal is risk neutral while the agent is risk averse, the principal will assign an identical number of employees to the local job centre irrespective of the state of nature.

Proposition 1: The central employment office assigns the same staff capacity to the local job center irrespective of the unemployment rate in the current period.

Further, it becomes obvious that at any contracting date $t$, the central employment office offers a contract on the spot that predefines the staff capacity of job centers contingent on the unemployment rate. The optimization problem is the same at any contracting date apart from the staff capacity that has been assigned in the previous period. Thus, the continuation budgeting plan consisting of sequential spot contracts is an optimal solution to the continuation contracting problem for the remaining periods and has a constant value over time. As this game with complete information in every period is a sub-game, we can reduce the dynamic model to consideration of a single period.

\footnotetext{
${ }^{9}$ For a more detailed exploration of the principle of optimal coinsurance, see Borch (1962).
} 
Proposition 2: At any date $t$ the contract is an optimal solution to the continuation contracting problem for the remaining periods. Therefore, it is sufficient to analyze the equilibrium policy decisions of the sub-game.

\section{Optimal Budgeting under Moral Hazard}

In this section we assume that the employment service $s_{t}$ as well as search effort $e_{t}$ are unobservable to the central employment office. Consequently, the latter cannot offer a contract that directly specifies search effort $e_{t}$ or employment service $s_{t}$. Instead, it can only write a contract contingent on the observable unemployment rate $U_{t}^{i}$. Due to this contract-specific environment it needs be worthwhile for the local job center to provide the desired level of service $s_{t}^{*}$. Otherwise, it may be expected to supply a lower level of effort that is unobservable to the principal. Hence, the central employment office budgeting strategy must meet the following incentive-compatibility constraint: (IC) $V\left(e\left(s_{t}^{*}, L_{t}^{i}\right)\right)+\delta p\left(\alpha_{1} \mid s_{t}^{*}\right) V\left(e\left(s_{t+1}, L_{t+1}^{1}\right)\right)+\delta p\left(\alpha_{2} \mid s_{t}^{*}\right) V\left(e\left(s_{t+1}, L_{t+1}^{2}\right)\right) \geq$ $V\left(e\left(s_{t}, L_{t}^{i}\right)\right)+\delta p\left(\alpha_{1} \mid s_{t}\right) V\left(e\left(s_{t+1}, L_{t+1}^{1}\right)\right)+\delta p\left(\alpha_{2} \mid s_{t}\right) V\left(e\left(s_{t+1}, L_{t+1}^{2}\right)\right)$ for all $s_{t} \geq s^{0}$.

The incentive-compatibility constraint (IC) tells us that it is not profitable for the job center to provide a level of service $s_{t}$ in period $t$ different to that $s^{*}$ desired by the central employment office. ${ }^{10}$ Accordingly, the latter must offer a lottery of staff capacity $L_{t+1}^{i}$ in period $t+1$ contingent on the state of the nature $i$ so that a particular service $s_{t}^{*}$ minimizes agents' expected costs:

$$
s_{t}^{*}=\arg \min \left\{\psi\left(e\left(s_{t}, L_{t}^{i}\right)\right)+p\left(\alpha_{1} \mid s_{t}\right) \psi\left(e\left(s_{t+1}, L_{t+1}^{1}\right)\right)+p\left(\alpha_{2} \mid s_{t}\right) \psi\left(e\left(s_{t+1}, L_{t+1}^{1}\right)\right)\right\}
$$

subject to $s_{t} \geq s^{0}$.

Assuming an interior solution the first order condition is as follows:

$$
p_{s}\left(\alpha_{1} \mid s_{t}^{*}\right)\left(\psi\left(e\left(s_{t+1}, L_{t+1}^{1}\right)\right)-\psi\left(e\left(s_{t+1}, L_{t+1}^{2}\right)\right)\right)=M C\left(s_{t}^{*}\left(e_{t}, L_{t}^{i}\right)\right)
$$

Most importantly, from the first order condition (8) we learn that the staff capacity in the lucky and unlucky cases must be fixed at a particular ratio. This ratio depends

\footnotetext{
${ }^{10}$ Note that we have assumed that the central employment office will implement a desired service level $s^{*}$ in the following period $t+1$ as well. Therefore we have replaced $V\left(e\left(s_{t+1}, L_{t+1}^{2}\right)\right)$ by $V\left(e\left(s^{*}, L_{t+1}^{2}\right)\right)$ in the incentive-compatibility constraint.
} 
crucially on the distribution of states $i$ in the following period as well as on the level of service $s_{t}^{*}$ and $s_{t+1}$ in the current period $t$ as well as in the following period $t+1$.

Let us in the interests of completeness consider the pathological case of a boundary solution. If the critical service level $s^{0}$ is relatively small, the cost of an additional unit of service level at $s=s^{0}$ borne by the job center can be higher than the benefits given by the right-hand-side of equation (8). In this case the job center will tend to choose the boundary service level $s^{0}$ and the central employment office cannot incentivize a higher service through an appropriate budgeting scheme. However, having distinguished the case of a critical service level $s^{0}$, the frame of our model clearly supports the interior solution given by equation (8).

\section{The optimal lottery of staff capacity in the following period}

For simplicity, we need first to solve a sub-problem of the central agency's minimization problem by focusing on the ratio of staff capacity that the central employment office will provide under the optimal budgeting mechanism. Accordingly, we assume that under moral hazard the service level $s_{t}{ }^{*}$ is implemented at the level of job centers. The reduced optimization problem of the central employment office is then the following:

$$
\min _{\left\{L_{t+1}^{1}, L_{t+1}^{2}\right\}} p\left(\alpha_{1} \mid s_{t}^{*}\right) \delta L_{t+1}^{1}+p\left(\alpha_{2} \mid s_{t}^{*}\right) \delta L_{t+1}^{2}
$$

subject to (WC) and equation (8), namely,

$$
p_{s}\left(\alpha_{1} \mid s_{t}^{*}\right)\left(\psi\left(e\left(s_{t+1}, L_{t+1}^{1}\right)\right)-\psi\left(e\left(s_{t+1}, L_{t+1}^{2}\right)\right)\right)=\operatorname{MC}\left(s^{*}\left(e_{t}, L_{t}^{i}\right)\right)
$$

and $s_{t} \geq s_{t}{ }^{*}$

Lagrange's method leads to the following first order conditions w.r.t. the capacity of the staff in $t+1$ contingent on $i$ :

$$
\begin{gathered}
M C\left(s_{t}^{*}\left(e_{t+1}, L_{t+1}^{1}\right)\right) s_{L}=\lambda_{\mathrm{t}}+\mu_{t} \frac{p_{s}\left(\alpha_{1} \mid s_{t}^{*}\right)}{p\left(\alpha_{1} \mid s_{t}^{*}\right)} \\
M C\left(s_{t}^{*}\left(e_{t+1}, L_{t+1}^{2}\right)\right) s_{L}=\lambda_{\mathrm{t}}-\mu_{t} \frac{p_{s}\left(\alpha_{1} \mid s_{t}^{*}\right)}{1-\mathrm{p}\left(\alpha_{1} \mid s_{t}^{*}\right)}
\end{gathered}
$$

If the Lagrange multiplier $\mu_{t}$ is equal to zero, we obtain the same result as in section III: agents are fully insured against the unlucky case. However, in the optimum the incentive-compatibility constraint is binding so that $\mu_{t}$ assumes a positive value. As a 
result, the risk averse job center is not fully insured against unlucky outcomes of the search process. If the unlucky case arises, insurance benefits to unemployed workers are substantial. In these circumstances, the central employment office shifts some risks on to the job center and reduces its wage bill below the level of the first-best case. In the event of the lucky case, however, the agent is rewarded and hence a staff capacity is assigned to it that is somewhat higher than in the first-best case.

In order to illustrate this result, we derive the central office's budgeting scheme from the first order conditions (9) and (10):

$$
\begin{aligned}
& L_{t+1}^{1}\left(\alpha_{1}\right)=\xi\left(\alpha_{1}\right) \\
& L_{t+1}^{2}\left(\alpha_{2}\right)=\xi\left(\alpha_{1}\right),
\end{aligned}
$$

where $\xi$ is the inverse function of the first order condition that is increasing in $\alpha_{i}$. Figure 1 depicts the functional form of the optimal budget scheme:

Figure 1: The second-best optimal budget scheme

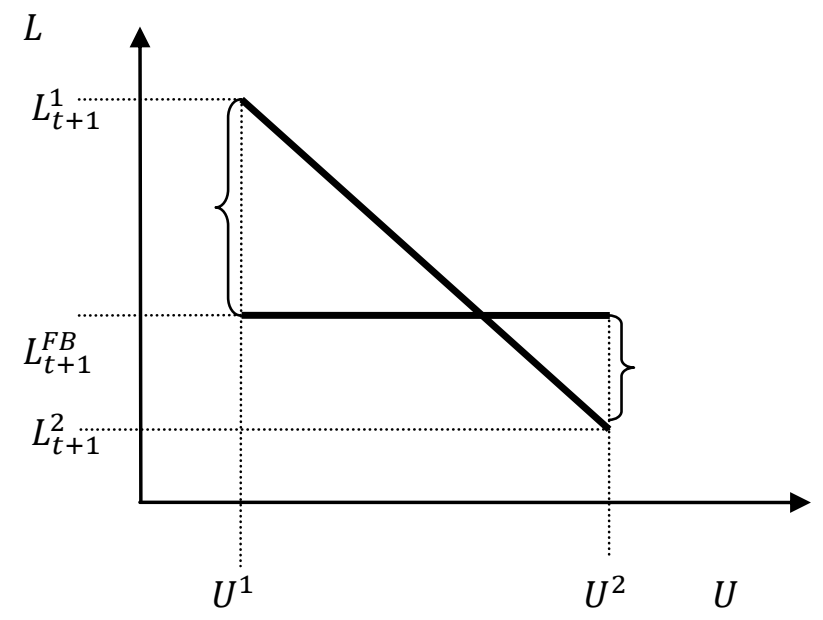

The horizontal line at $L_{t+1}^{F B}$ signifies the first-best optimal scheme which by proposition 3 assigns an equal work force to centers with high as well as low output. Under moral hazard, job centers are only partly insured against labor market shocks. Therefore the budget scheme is a decreasing function of the unemployment rate with a budget $L_{t+1}^{1}$ $\left(L_{t+1}^{2}\right)$ if unemployment rate $U_{1}\left(U_{2}\right)$ occurs. The slope of the budget constraint depends crucially on the capacity in the previous period $t$ as we have already derived in lemma 1. 
The slope is relatively flat if the capacity in the previous period is relatively high and conversely.

Proposition 3: The central employment office offers a budget scheme in which a higher staff capacity is assigned to the job center than in the first-best optimal case if the unemployment rate is low and a lower capacity than in the first-best optimal case if the unemployment rate is high.

Proof: see Appendix A.4.

Further, we can derive that the slope of the budgeting scheme must be sufficiently steep. Due to the convexity of the disutility function, a risk premium must be paid to the risk averse agent in order to meet the work load constraint since that agent is now confronted with a lottery $\left\{\mathrm{L}_{\mathrm{t}+1}^{1} \mathrm{~L}_{\mathrm{t}+1}^{2}\right\}$. From Jensen's inequality, we can establish that

$$
\begin{gathered}
p\left(\alpha_{1} \mid s_{t}\right) \psi\left(e\left(s_{t+1}, L_{t+1}^{1}\right)\right)+p\left(\alpha_{2} \mid s_{t}\right) \psi\left(e\left(s_{t+1}, L_{t+1}^{2}\right)\right)< \\
\psi\left(e\left(s_{t+1}, p\left(\alpha_{1} \mid s_{t}\right) L_{t+1}^{1}+p\left(\alpha_{2} \mid s_{t}\right) L_{t+1}^{2}\right)\right)
\end{gathered}
$$

obtains. The expected staff capacity that meets the work load capacity must be larger if the budgeting scheme offered shifts some risk on to the agent. According to the budgeting scheme depicted in the figure the difference between the first best optimal work force $L_{t+1}^{F B}$ and the work force $L_{t+1}^{1}$ offered in the "lucky case" is greater than the difference between the first best optimal work force $L_{t+1}^{F B}$ and the work force $L_{t+1}^{2}$ offered in the "unlucky case" under moral hazard. ${ }^{11}$

An important concern in the practical application is that a local job center that faces the "lucky case" consecutively for several periods does not accumulate a large staff. We believe that such a budget cannot be supported in the political process. However,

\footnotetext{
11 The existence of a risk premium implies that there is a tradeoff between incentivizing job centers to exert search effort and insuring them against labor market shocks. In this sense it may be profitable for the central employment office to reduce the level of desirable service $s^{*}$. This may go along with an optimal incentive scheme that shifts less risk on to local job centers and hence entails a lower risk prime necessary to fulfill the work load constraint. However, in the present treatment we focus on the implementation of an exogenously given service level because there are many other factors determining the desirable level of service apart from the monetary cost borne by the central employment office (consider the sociological, political, and psychological arguments that can be advanced to justify a high level of service provision) and which the underlying partial equilibrium model abstracts from. Instead, the proper budgeting scheme that assigns a lottery of staff capacity to job centers does not alter important factors of the labor market. Hence, we believe that alterations to the workforce can be made in an institutionally acceptable way.
} 
our underlying budget mechanism precludes the accumulation of staff capacity over a longer period of time.

In particular, the central employment office offers budgeting schemes on the spot, as it can tailor its budgeting scheme in each period contingent on the current capacity. In Appendix A.5 we show that the aforementioned risk premium is a decreasing function of the capacity available in the current period $t$. In this case, the Lagrange multiplier $\mu_{t}$ will assume a relatively high value if capacity $L_{t}^{i}$ is low and conversely if capacity $L_{t}^{i}$ is high. We can state the following proposition:

Proposition 4: If staff capacity in the current period is very high, the optimal budgeting strategy for the following period entails a small wedge between the staff capacity in the following period $t+1$ for the lucky case $L_{t+1}^{1}$ and for the unlucky case $L_{t+1}^{2}$, respectively

\section{Proof: see Appendix A.5}

The economic intuition behind this result is as follows. If the job center faces a high capacity in the current period, the marginal cost of providing the service is relatively low. Hence, incentivizing search effort on the part of the job center is not a major issue. The central employment office merely needs to shift risk to the job center to a small extent and the underlying risk premium is of little account.

\section{Conclusion}

The purpose of this study has been to analyze a fundamental delegation problem inherent in the public employment service. Typically, local job centers commissioned to serve as match makers in imperfect labor markets enjoy some discretion in reducing their work load because neither their search intensity in linking job seekers to vacancies nor the resulting contact rate is verifiable by the central agency. Poor institutional performance, as well as high rates of matching unemployment, might therefore result. To deal with the problem of moral hazard in public employment service institutions we employ a search-theoretic model in which the central agency must provide incentives to increase the search effort of local job centers and hence the contact rate. Using a mechanism design approach, we propose a budgeting scheme wherein greater staff capacity is provided to successful agencies achieving high matching rates. 
So as to facilitate exposition we have considered a rather stylized model, the results of which are nonetheless valid in a generalized framework. For example, the real world context of the present treatment is a milieu in which the principal (the central employment office) cannot pay any direct monetary transfers to its agents (local job centers). We have shown how the principal can circumvent this institutional constraint by designing a budgeting scheme that assigns additional staff to the job center in future periods. And what of the optimal budgeting strategy in regimes where both monetary transfers and additional staff can be deployed to achieve the risk prime? It is straightforward to show in this case that it is optimal for the principal to allocate staff to the local job center in a first-best optimal manner and pay a monetary transfer in order to meet the workload constraint.

Further, we have assumed that the principal can only commit to a policy to be implemented in the following period $t+1$. That said, it is again straightforward to show that the results presented here also hold if the principal can commit to offer a contract pre-committing staffing levels for a countable number of future periods. The principal has no incentive to postpone the assignment of additional staff which is necessary to secure the risk prime staff into the future. Moreover, our analysis can be extended to encompass more than the two states of nature considered here. To this end, however, we would have to assume that the monotonous likelihood ratio property be fulfilled in addition to first-order stochastic dominance. 


\section{Appendices}

(A.1) The expected unemployment rate is given by $E\left[U_{i} \mid s\right]=p\left(\alpha_{1} \mid s\right)\left(b \cdot U_{1}-L_{1}\right)+$ $p\left(\alpha_{2} \mid s\right)\left(b \cdot U_{2}-L_{2}\right)$. For the binary case, first-order stochastic dominance is fulfilled if $p_{s}\left(\alpha_{1} \mid s\right)<0$ and $p_{S S}\left(\alpha_{1} \mid s\right)>0$. Then, $\frac{\partial E\left[U_{i} \mid s\right]}{\partial s}>0$ and $\frac{\partial E\left[U_{i} \mid s\right]}{\partial s s}<0$, so that the stochastic output function with input $s$ has the conventional properties.

(A.2) Due to the concavity of the intermediate production function, the effort level necessary to produce the desired $\mathrm{s}^{*}$ in the lucky case in period $\mathrm{t}$ [i.e. $\left.e\left(s^{*}, L_{t}^{1}\right)\right]$ exceeds the effort level in the unlucky case in period t [ i.e. $\left.e\left(s^{*}, L_{t}^{2}\right)\right]$. Therefore, the cost of providing $\mathrm{s}^{*}$ is higher in the unlucky case, and calls for a more opportune lottery in the following period $t+1$.

(A.3) The job center which decides to provide a level of service $s$ see itself confronted with the following constraint cost minimization problem. It minimizes effort $\operatorname{cost} \psi\left(e_{t}\right)$ subject to a given level of service and a given work force.

$$
\mathcal{L}\left(e_{t}\right)=\psi\left(e_{t}\right)-\vartheta\left\{s\left(L_{t}^{i}, e_{t}\right)-\bar{s}\right\},
$$

where $\vartheta$ is the Lagrange multiplier. Then, the first order condition can be written:

$$
\operatorname{MC}\left(s_{t}\right)=\frac{\psi^{\prime}\left(e_{t}\right)}{s_{e}\left(L_{t}^{i}, e_{t}\right)} .
$$

Using the envelope theorem we can derive that $\operatorname{MC}\left(s_{t}, L_{t}^{a}\right)$ exceeds $\operatorname{MC}\left(s_{t}, L_{t}^{b}\right)$ for all $L_{t}^{a}$ smaller than $L_{t}^{b}$.

(A.4) By first order stochastic dominance we can derive the following inequality:

$$
\frac{p_{s}\left(\alpha_{1} \mid s_{t}^{*}\right)}{p\left(\alpha_{1} \mid s_{t}^{*}\right)}<\frac{p_{s}\left(\alpha_{1} \mid s_{t}^{*}\right)}{1-p\left(\alpha_{1} \mid s_{t}^{*}\right)}<0
$$

Adding up equations (10) and (11) yields:

$$
\operatorname{MC}\left(s^{*}\left(e_{t}, L_{t+1}^{1}\right)\right) s_{L}-\operatorname{MC}\left(s^{*}\left(e_{t}, L_{t+1}^{2}\right)\right) s_{L}=\mu_{t}\left(\frac{p_{s}\left(\alpha_{1} \mid s_{t}^{*}\right)}{p\left(\alpha_{1} \mid s_{t}^{*}\right)}-\frac{p_{s}\left(\alpha_{1} \mid s_{t}^{*}\right)}{1-\mathrm{p}\left(\alpha_{1} \mid s_{t}^{*}\right)}\right)
$$

By Appendix A.2 the left hand side-value of equation (12) is negative if $L_{t+1}^{1}$ exceeds $L_{t+1}^{2}$. In this case the multiplier $\mu_{t}$ on the right-hand side must take a positive value as the term in brackets is negative. 
(A.5) Let us assume that the staff capacity goes to infinity. Then the marginal productivity of effort $s_{e}\left(L_{t}^{i}, e_{t}\right)$ will converge to a very high value, denoted by $\rho$. The agent's marginal cost of service provision thus converges to the limit value $\lim _{\mathrm{L} \rightarrow \infty}(\mathrm{MC}(s))=\frac{\psi^{\prime}\left(e_{t}\right)}{\rho}$. As the cost of an additional unit $s$ borne by the agent approximates a relatively low value, the multiplier $\mu_{\mathrm{t}}$ converges to low value as well. Accordingly, the optimal budgeting scheme under moral hazard does not entail a high wedge between the staff capacity in the following period $t+1$, namely $L_{t+1}^{1}$ and $L_{t+1}^{2}$. 


\section{References}

Addison, John T. and Pedro Portugal. 2002. "Job Search Methods and Outcomes." Oxford Economic Papers, vol. 54: 3, pp. 505-533.

Bishop, John H. 1993. "Improving Job Matches in the U.S. Labor Market." Brookings Papers on Economic Activity, Microeconomics Volume 1, pp. 335-400.

Blau, David M., and Phillip K. Robbins. 1990. “Job Search Outcomes for the Employed and Unemployed." Journal of Political Economy, vol. 98: 3, pp. 637-635.

Borch, Karl. 1962. “Equilibrium in an Insurance Market.” Econometrica, vol. 30: 3, pp. 424-444.

Chiappori, Paul-André, Ines Macho, Patrick Rey, and Bernard Salanié. 1994. "Repeated Moral Hazard: The Role of Monetary Commitment and the Access to Credit Markets." European Economic Review, vol. 38: 8, pp. 1527-53.

Gronau, Reuben. 1971. "Information and Frictional Unemployment." American Economic Review, 1971, 61: 3, pp. 290-301.

Gregg, Paul, and Jonathan Wadsworth. 1996. "How Effective Are State Employment Agencies? Jobcentre Use and Job Matching in Britain." Oxford Bulletin of Economics and Statistics, vol. 58: 3, pp. 443-67.

Jones, Stephen R.G. 1988. "Job Search Methods, Intensity and Effects." Oxford Bulletin of Economics and Statistics, vol. 51: 3, pp. 277-296

Lippman, Steven A. and John J. McCall. 1976. "Job Search in a Dynamic Economy.” Journal of Economic Theory, vol. 12: 3, pp. 365-90.

McCall, John J. 1970. “Economics of Information and Job Search.” Quarterly Journal of Economics, vol. 84: 1, pp. 113-26.

Merz, Monika. 1995. "Search in the Labor Market and the Real Business Cycle." Journal of Monetary Economics, vol. 36: 2, 269-300.

Mortensen, Dale T. 1986. “Job Search and Labor Market Analysis.” In Orley Ashenfelter and Richard Layard, eds., Handbook of Labor Economics, Volume 2. Amsterdam: North Holland, pp. 849-919.

Petrongolo, Barbara, and Christopher A. Pissarides. 2001. "Looking into the Black Box: A Survey of the Matching Function." Journal of Economic Literature, vol. 39: 2, pp. 390-431.

Rogerson, Richard, Robert Shimer, and Randall Wright. 2004. "Search-Theoretic Models of the Labor Market: A Survey.” NBER Working Paper 10655. Cambridge, MA: National Bureau of Economic Research, July.

Shapiro, Carl and Stiglitz, Joseph E. 1984. "Equilibrium Unemployment as a Worker Discipline Device." American Economic Review, vol. 74: 3, pp. 433-444. 
Sheldon George M. 2003. " The Efficiency of Public Employment Services: A Nonparametric Matching Function Analysis for Switzerland." Journal of Productivity Analysis, vol. 20: 1, pp. 49-70.

Thomas, Jonathan M. 1997. "Public Employment Agencies and Unemployment Spells: Reconciling the Experimental and Nonexperimental Evidence." Industrial and Labor Relations Review, vol. 50: 4, pp. 667-683.

Walsh, Carl E. 1995. "Optimal Contracts for Central Bankers." American Economic Review, vol. 85:1, pp. 150-67.

Wielgosz, John B., and Susan Carpenter. 1988. "The Effectiveness of Alternative Methods of Searching for Jobs and Finding Them." American Journal of Economics and Sociology, vol. 46: 2, pp. 151-164.

Winter-Ebmer, Rudolph. 1991. "Some Micro Evidence on Unemployment Persistence." Oxford Bulletin of Economics and Statistics, vol. 53: 1, pp. 27-43. 